\title{
Space Signal Processing for Helicopter Satellite Communication using 2x1 Alamouti Scheme
}

\author{
Mohamed Ismail Ibrahim \\ Communications Engineering \\ Department \\ Teaching Assistant \\ Modern Academy for Engineering \\ and Technology \\ Cairo, Egypt
}

\author{
Khairy A. EIBarbary \\ Communications Engineering \\ Department \\ Professor \& Head of Electric \\ Engineering Department \\ Canal University \\ Ismailia, Egypt
}

\author{
Abdelhamid Gaafar \\ Communications Engineering \\ Department \\ Dean of Productivity \& Quality \\ Institute \\ ASST- Arab Academy for \\ Science, Technology \& Maritime \\ Transport \\ Cairo, Egypt
}

\begin{abstract}
In helicopter satellite communications, the periodic blockage of the received signal and the carrier frequency fluctuations are the most important problems. This paper propose the space signal processing with time diversity combining scheme for helicopter satellite communications. In the proposed scheme, a space signal processing combining with time diversity tracks the carrier frequency fluctuations due to Doppler shift . Results of computer simulation show that the proposed scheme improves the BER performance of the previous conventional scheme.
\end{abstract}

\section{General Terms}

Communications, Digital signal processing, Software

\section{Keywords}

Space signal processing using Alamouti scheme, AFC (Automatic Frequency Control) and Tapped delay line

\section{INTRODUCTION}

Emergency rescue and disaster relief are important applications of helicopters. To establish reliable communications in these applications, helicopter satellite communications are attractive.

One of the most important problems in helicopter satellite communications is periodic blockage of the signal due to rotor blades. This causes BER performance degradation and cycle-slip of the recovered carrier, to overcome the problem, we proposed the space signal processing with time diversity combining scheme The scheme achieves good BER performance [4]. Also the proposed transversal filter which also cancels Doppler offset of the received signal caused by helicopter maneuvers, As a result BER performance is improved .

In this paper, to improve the BER performance using two transmit and one receiving antennas such that the BER performance is more improved, space-time processing radio operates simultaneously on multiple antennas by processing both in space and time.

The paper is organized as follows. The communication system model is illustrated in section 2. The proposed scheme is described in section 3 . In section 4 , we show results of the computer simulation of the space time characteristics and the BER performance. Finally, conclusion of the paper in section 5 .

\section{COMMUNICATION SYSTEM MODEL}

As mentioned previously, one of the most important problems in helicopter satellite communications is the periodic blockage of the signal due to rotor blades. Fig. 1 shows the periodic blockage model.

The blockage period $\mathrm{T}_{\mathrm{p}}$ and the blockage duration $\mathrm{T}_{\mathrm{d}}$ are constant dependent on the type of helicopter, respectively.

$\mathrm{T}_{\mathrm{p}}$ : blockage period

$\mathrm{T}_{\mathrm{d}}$ : blockage duration

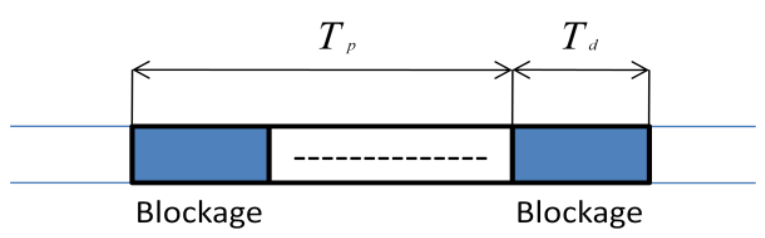

Fig. 1. Periodic blockage model

Fig. 2 shows the communication system model employing predetection combining. In Fig. 2, a binary information data sequence $\{$ ui $\}$ is encoded by convolutional encoder with coding rate $1 / 2$, and binary encoded data sequences $\{\mathrm{pi}\}$ and $\{\mathrm{qi}\}$ are produced. Then, a fixed delay $\mathrm{mT}_{b}$ is given to the encoded data sequence $\{q \mathrm{i}\}$, where $\mathrm{m}$ is a positive integer and $\mathrm{T}_{\mathrm{b}}$ is the bit duration of the information data. This is the first time diversity processing. choosing the nearest integer of $T_{p} /\left(4 T_{b}\right)$ as $m$ because it is the delay achieving the best BER performance after Viterbi decoding in the receiver. After parallel-to-serial conversion of the encoded data sequences, the second time diversity processing is performed. That is, the encoded data sequence after parallel-to-serial conversion is duplicated, and a fixed delay $2 \mathrm{mT}_{\mathrm{b}}$ is given to the duplicated sequence. These two sequences are multiplexed to a binary transmitted data sequence \{ai\} by parallel-to-serial conversion. The encoded sequences \{pi\}, \{qi\} and the transmitted data sequence $\{a \mathrm{a}\}$ have the following relations:

$$
\left.\begin{array}{c}
\mathrm{a}_{4 \mathrm{i}}=\mathrm{p}_{\mathrm{i}} \\
\mathrm{a}_{4 \mathrm{i}+1}=\mathrm{p}_{\mathrm{i}-2 \mathrm{~m}} \\
\mathrm{a}_{4 \mathrm{i}+2}=\mathrm{q}_{\mathrm{i}-\mathrm{m}} \\
\mathrm{a}_{4 \mathrm{i}+3}=\mathrm{q}_{\mathrm{i}-3 \mathrm{~m}}
\end{array}\right\}
$$

From Eq. (1) expressing the time diversity process in Fig. 3 


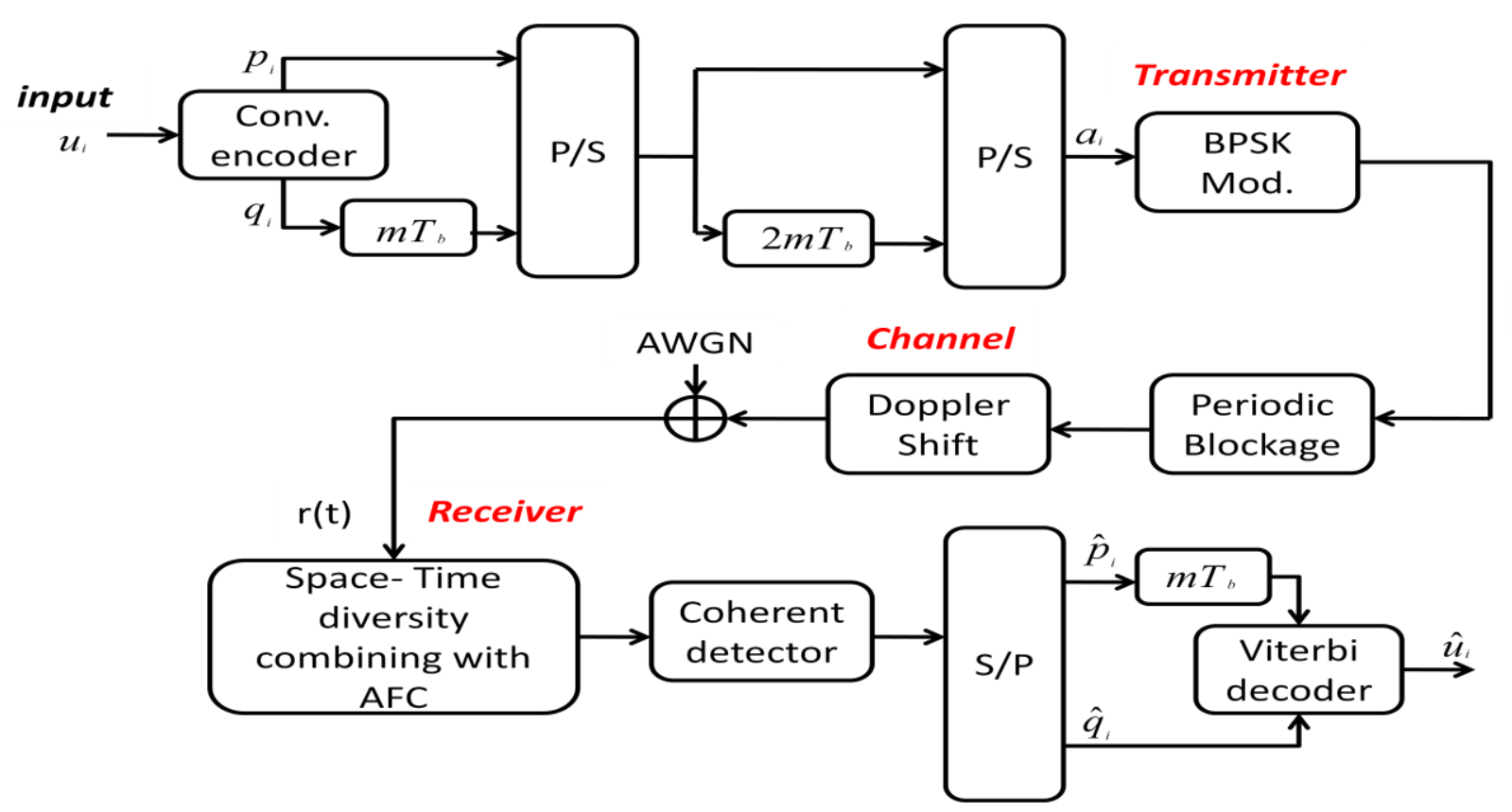

Fig.2 Communication system model

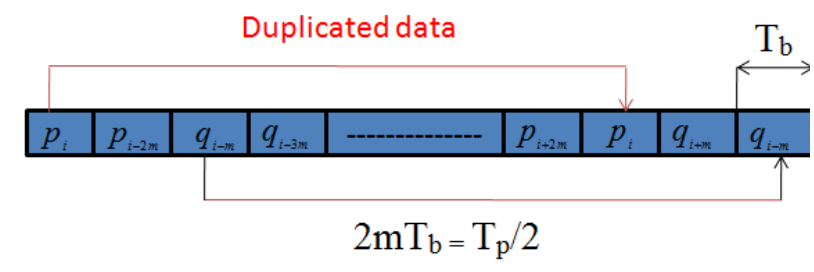

Fig.3 Time Diversity Process

Then, the transmitted data sequence $\left\{a_{i}\right\}$ is modulated in the BPSK modulator, and the transmitted signal $s(t)$ is generated. The transmitted signal is represented by

$$
\begin{gathered}
\mathrm{s}\left(\mathrm{iT}_{\mathrm{b}}\right)=\sqrt{\mathrm{E}_{\mathrm{s}}} \exp \left(-\mathrm{jp}_{\mathrm{i}} \pi\right) \\
\mathrm{s}\left(\mathrm{iT}_{\mathrm{b}}+\mathrm{T}_{\mathrm{s}}\right)=\sqrt{\mathrm{E}_{\mathrm{s}}} \exp \left(-\mathrm{jp}_{\mathrm{i}-2 \mathrm{~m}} \pi\right) \\
\mathrm{s}\left(\mathrm{iT}_{\mathrm{b}}+2 \mathrm{~T}_{\mathrm{s}}\right)=\sqrt{\mathrm{E}_{\mathrm{s}}} \exp \left(-\mathrm{jq}_{\mathrm{i}-\mathrm{m}} \pi\right) \\
\mathrm{s}\left(\mathrm{iT}_{\mathrm{b}}+3 \mathrm{~T}_{\mathrm{s}}\right)=\sqrt{\mathrm{E}_{\mathrm{s}}} \exp \left(-\mathrm{jq}_{\mathrm{i}-3 \mathrm{~m}} \pi\right)
\end{gathered}
$$

Where $E_{s}=E_{b} / 4, \quad E_{b}$ is the signal energy per bit of the information data sequence $\left\{\mathrm{u}_{\mathrm{i}}\right\}$ and $\mathrm{T}_{\mathrm{s}}=\mathrm{T}_{\mathrm{b}} / 4$. In the transmission channel, the transmitted signal $s(t)$ is periodically blocked and Doppler shifted. Furthermore, the additive white Gaussian noise (AWGN) with single-sided noise power spectral density $\mathrm{N}_{\mathrm{o}}$ is added to the signal, resulting in the received signal $r(t)$. If constant Doppler shift $f$ is assumed, the received signal $r(t)$ is represented by

$$
\begin{array}{r}
r(t)=\sum_{-\infty}^{\infty} h\left(t-\mathrm{nT}_{\mathrm{p}}\right) \mathrm{s}(\mathrm{t}) \exp (-\mathrm{j} 2 \pi \mathrm{ft})+\mathrm{n}(\mathrm{t}) \\
\mathrm{h}(\mathrm{t})=\left\{\begin{array}{cc}
1 & \left(\mathrm{~T}_{\mathrm{d}} \leq \mathrm{t}<\mathrm{T}_{\mathrm{p}}\right) \\
0 & \text { (else) }
\end{array}\right.
\end{array}
$$

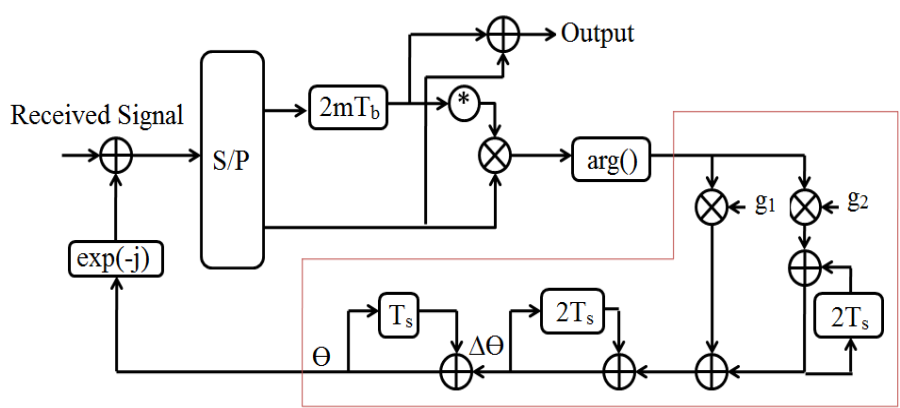

Fig.4 Configuration of conventional scheme

In the receiver, Doppler shift of the receiver signal is firstly removed by $\mathrm{AFC}$, and in-phase combining corresponding to the second time diversity processing in the transmitter is performed. After coherent detection of the combined received signal, the serial-to-parallel converter produces binary sequences $\left\{\widehat{p}_{1}\right\}$ and $\left\{\widehat{q}_{1}\right\}$ corresponding to the encoded sequence $\{\mathrm{pi}\}$ and $\{\mathrm{qi}\}$, respectively. In addition, a fixed delay $\mathrm{mT}_{\mathrm{b}}$ is given to the sequence $\{\mathrm{pi}$. It corresponds to the first time diversity processing in the transmitter, and gives time diversity effect to the branch metric calculation in the Viterbi decoder.

\section{CONVENTIONAL SCHEME}

Fig. 4 shows the configuration of the conventional AFC scheme, achieving pre-detection combining in the environment of helicopter satellite communications . In Fig. 4, the conventional frequency error detector is described in red line. Let denote ri the discrete received signal. That is,ri $=r(i T s)$. Hereafter, assuming that no signal blockage, no AWGN and constant Doppler shift $\mathrm{f}$ for simplicity. On the assumption, the following relations are held: 


$$
\begin{aligned}
r_{4 i} & =r\left(i T_{b}\right) \\
= & \sqrt{E_{s}} \exp \left[-j \pi\left(p_{i}+2 f_{i} T_{b}\right)\right] \\
r_{4 i+1}= & r\left(i T_{b}+T_{s}\right) \\
= & \sqrt{E_{s}} \exp \left\{-j \pi\left[p_{i-2 m}+2 f\left(i_{b}+T_{s}\right)\right]\right\}
\end{aligned}
$$

(5)

$$
\begin{aligned}
\mathrm{r}_{4 \mathrm{i}+2} & =\mathrm{r}\left(\mathrm{iT}_{\mathrm{b}}+2 \mathrm{~T}_{\mathrm{s}}\right) \\
& =\sqrt{\mathrm{E}_{\mathrm{s}}} \exp \left\{-\mathrm{j} \pi\left[\mathrm{q}_{\mathrm{i}-\mathrm{m}}+2 \mathrm{f}\left(\mathrm{iT}_{\mathrm{b}}+2 \mathrm{~T}_{\mathrm{s}}\right)\right]\right\} \\
\mathrm{r}_{4 \mathrm{i}+3}= & \mathrm{r}\left(\mathrm{iT}_{\mathrm{b}}+3 \mathrm{~T}_{\mathrm{s}}\right) \\
& =\sqrt{\mathrm{E}_{\mathrm{s}}} \exp \left\{-\mathrm{j} \pi\left[\mathrm{q}_{\mathrm{i}-3 \mathrm{~m}}+2 \mathrm{f}\left(\mathrm{iT}_{\mathrm{b}}+3 \mathrm{~T}_{\mathrm{s}}\right)\right]\right\}
\end{aligned}
$$

In Fig. 4, the phase rotation of the discrete received signal ri is performed for Doppler shift removal firstly. Then, serial- toparallel converter produces two signal sequences $\{\alpha \mathrm{i}\}$ and $\{\beta \mathrm{i}\}$. In the initial state (i.e. no phase rotation), these signals can be represented by

$$
\begin{gathered}
\alpha_{2 \mathrm{i}}=\mathrm{r}_{4 \mathrm{i}} \\
\beta_{2 \mathrm{i}}=\mathrm{r}_{4 \mathrm{i}+1} \\
\alpha_{2 \mathrm{i}+1}=\mathrm{r}_{4 \mathrm{i}+2} \\
\beta_{2 \mathrm{i}+1}=\mathrm{r}_{4 \mathrm{i}+3}
\end{gathered}
$$

Next, the fixed delay $2 \mathrm{mTb}$ is given to the signal sequence $\{\alpha \mathrm{i}\}$. The delayed sequence $\{\alpha \mathrm{i}\}$ is added to the other sequence $\{\beta \mathrm{i}\}$, resulting in the combined output signal. When Doppler shift is exactly removed, the in-phase combining, maximizing signal-tonoise power ratio of the combined signal, is achieved. On the other hand, the complex conjugate of the delayed sequence $\{\alpha \mathrm{i}\}$ is multiplied by the other sequence $\{\beta \mathrm{i}\}$, resulting in the phase difference sequence \{ei\}. From Eq. (5) and (6), having

$$
\begin{aligned}
\mathrm{e}_{2 \mathrm{i}} & =\alpha_{2 \mathrm{i}-2 \mathrm{~m}}^{*} \beta_{2 \mathrm{i}} \\
& =\mathrm{r}_{4 \mathrm{i}-2 \mathrm{~m}}^{*} \mathrm{r}_{4 \mathrm{i}+1} \\
& =\mathrm{E}_{\mathrm{s}} \exp \left[-\mathrm{j} 2 \pi \mathrm{f}\left(2 \mathrm{mT}_{\mathrm{b}}+\mathrm{T}_{\mathrm{s}}\right)\right] \\
\mathrm{e}_{2 \mathrm{i}+1}= & \alpha_{2 \mathrm{i}-2 \mathrm{~m}+1}^{*} \beta_{2 \mathrm{i}+1} \\
& =\mathrm{r}_{4 \mathrm{i}-2 \mathrm{~m}-2}^{*} \mathrm{r}_{4 \mathrm{i}+3} \\
& =\mathrm{E}_{\mathrm{s}} \exp \left[-\mathrm{j} 2 \pi \mathrm{f}\left(2 \mathrm{mT}_{\mathrm{b}}+\mathrm{T}_{\mathrm{s}}\right)\right]
\end{aligned}
$$

It is clear that the argument of the phase difference sequence $\{$ ei $\}$ is proportional to Doppler shift $\mathrm{f}$. That is

$$
\arg \left(\mathrm{e}_{\mathrm{i}}\right)=2 \pi \mathrm{f}\left(2 \mathrm{mT}_{\mathrm{b}}+\mathrm{T}_{\mathrm{s}}\right)
$$

Where $\arg (\cdot)$ denotes the argument of the complex signal, can thus estimate Doppler shift exactly based on the argument, the second order feedback loop tracks and removes Doppler shift. Then, as mentioned above, the in-phase combining is achieved.

\section{PROPOSED SCHEME}

The proposed space time diversity combining scheme with accurate tapped delay line, achieving pre-detection combining in the environment of helicopter satellite communications. Fig. 5 shows the proposed scheme. In the scheme, the tapped delay line tracks and removes Doppler shift accuracy and the space time (ST) processing can increase array gain and improve diversity.

$$
\widehat{\theta}=\sum_{\mathrm{k}=0}^{5} \mathrm{C}_{\mathrm{k}} \mathrm{x}[\mathrm{n}-\mathrm{k}]
$$

Such that From analysis of the AFC have the tapped delay line coefficients

$$
\begin{aligned}
& C_{0}=C_{1}=g_{1}+g_{2} \\
& C_{2}=C_{3}=g_{1}+2 g_{2} \\
& C_{4}=C_{5}=g_{2}
\end{aligned}
$$

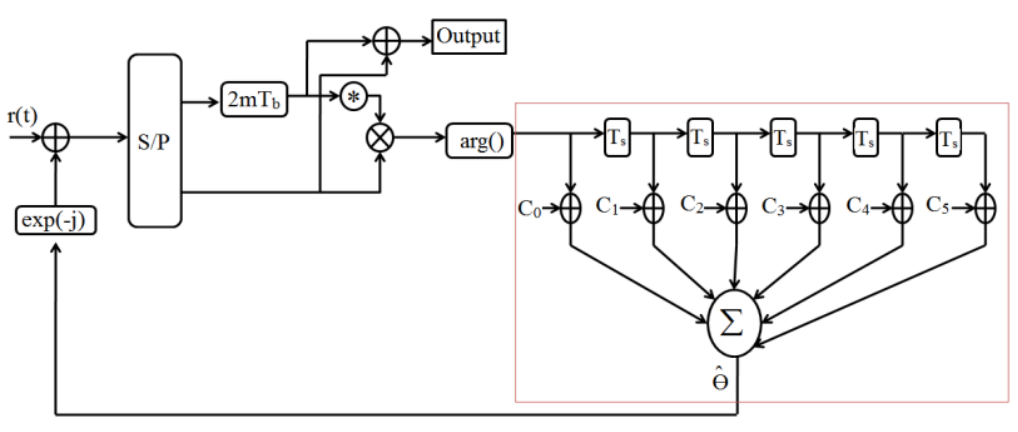

Fig.5 Configuration of proposed scheme

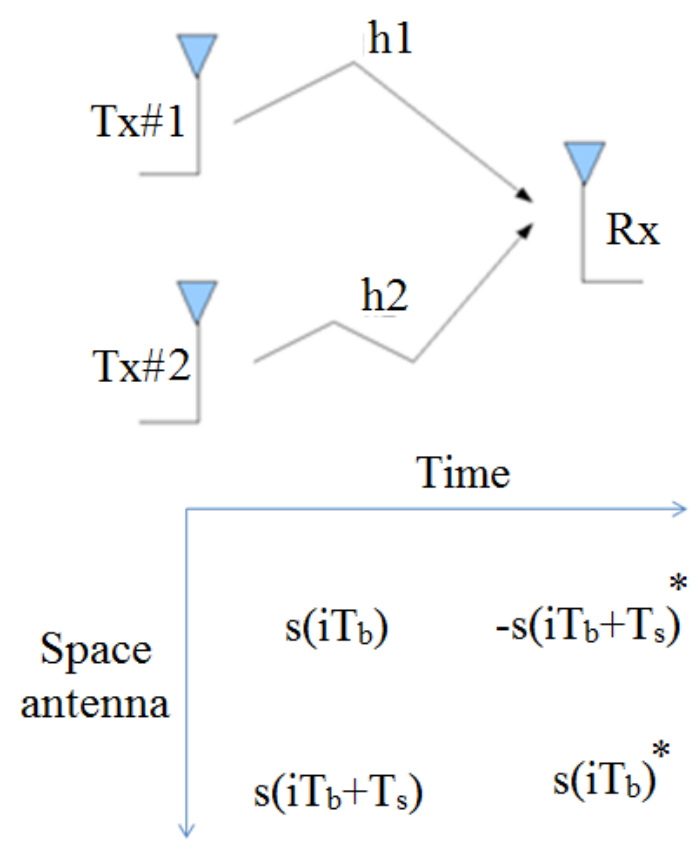

Fig.6 Configuration of 2x1 Alamouti scheme

Fig .6 shows the configuration of of $2 \times 1$ Alamouti scheme which is the proposed scheme. In this case of transmission considering that having a transmission sequence $\mathrm{s}\left(\mathrm{iT}_{\mathrm{b}}\right), \mathrm{s}\left(\mathrm{iT}_{\mathrm{b}}+\right.$ $\mathrm{Ts}, \mathrm{siTb}+2 \mathrm{Ts}, \mathrm{s}(\mathrm{iTb}+3 \mathrm{Ts})$....etc.

Alamouti suggested that grouping the symbols into groups of two. In the first time slot, send $s\left(\mathrm{iT}_{\mathrm{b}}\right)$ and $\mathrm{s}\left(\mathrm{iT}_{\mathrm{b}}+\mathrm{T}_{\mathrm{s}}\right)$ from the first and second antenna respectively. In second time slot send $-s\left(\mathrm{iT}_{\mathrm{b}}+\mathrm{T}_{\mathrm{s}}\right)^{*}$ and $\mathrm{s}\left(\mathrm{iT}_{\mathrm{b}}\right)^{*}$ from the first and second antenna respectively. In the third time slot send $s\left(\mathrm{iT}_{\mathrm{b}}+2 \mathrm{~T}_{2}\right)$ and $\mathrm{s}\left(\mathrm{iT}_{\mathrm{b}}+3 \mathrm{~T}_{2}\right)$ from the first and second antenna. In fourth time slot, send $-\mathrm{s}\left(\mathrm{iT}_{\mathrm{b}}+3 \mathrm{~T}_{\mathrm{s}}\right)^{*}$ and $\mathrm{s}\left(\mathrm{iT}_{\mathrm{b}}+2 \mathrm{~T}_{\mathrm{s}}\right)^{*}$ from the first and 
second antenna and so on. Notice that though grouping two symbols, still need two time slots to send two symbols, hence, there is no change in the data rate.

Assuming that the channel is a flat fading Rayleigh multipath channel so the following equations are held:

For the first two time slots:

$$
\begin{aligned}
& \alpha_{2 i}=h_{1} s\left(i T_{b}\right) e^{-j 2 \pi f_{d} i T_{b}} \\
& +h_{2} s\left(i T_{b}+T_{s}\right) e^{-j 2 \pi f_{d}\left(i T_{b}+T_{s}\right)} \\
& +n 1
\end{aligned}
$$

The received signal on the second time slot is:

$$
\begin{array}{rl}
\beta_{2 i}=-h_{2} & s\left(i T_{b}+T_{s}\right)^{*} e^{-j 2 \pi f_{d}\left(i T_{b}+T_{s}\right)} \\
& +h_{1} s\left(i T_{b}\right)^{*} e^{-j 2 \pi f_{d}\left(i_{b}\right)} \\
& +n 2
\end{array}
$$

$$
=\left[\begin{array}{ll}
h_{1} & h_{2}
\end{array}\right]\left[\begin{array}{c}
-s\left(i T_{b}+T_{s}\right)^{*} e^{-j 2 \pi f_{d}\left(i T_{b}+T_{s}\right)} \\
s\left(i T_{b}\right)^{*} e^{-j 2 \pi f_{d}\left(i T_{b}\right)}
\end{array}\right]+
$$

n2

For the second two time slots:

$$
\begin{aligned}
& \alpha_{2 i+1} \\
& =\mathrm{h}_{1} \mathrm{~s}\left(\mathrm{iT}_{\mathrm{b}}+2 \mathrm{~T}_{\mathrm{s}}\right) \mathrm{e}^{-\mathrm{j} 2 \pi \mathrm{f}_{\mathrm{d}}\left(\mathrm{iT}_{\mathrm{b}}+2 \mathrm{~T}_{\mathrm{s}}\right)} \\
& +h_{2} s\left(i_{b}+3 T_{s}\right) e^{-j 2 \pi f_{d}\left(i T_{b}+3 T_{s}\right)} \\
& +\mathrm{n} 1 \\
& =\left[\begin{array}{ll}
h_{1} & h_{2}
\end{array}\right]\left[\begin{array}{c}
s\left(\mathrm{iT}_{\mathrm{b}}+2 \mathrm{~T}_{\mathrm{s}}\right) \mathrm{e}^{-\mathrm{j} 2 \pi \mathrm{f}_{\mathrm{d}}\left(\mathrm{iT}_{\mathrm{b}}+2 \mathrm{~T}_{\mathrm{s}}\right)} \\
\mathrm{s}\left(\mathrm{iT}_{\mathrm{b}}+3 \mathrm{~T}_{\mathrm{s}}\right) \mathrm{e}^{-\mathrm{j} 2 \pi \mathrm{f}_{\mathrm{d}}\left(\mathrm{iT}_{\mathrm{b}}+3 \mathrm{~T}_{\mathrm{s}}\right)}
\end{array}\right]+
\end{aligned}
$$

n3

The received signal on the 4th time slot is:

$$
\begin{aligned}
& \beta_{2 \mathrm{i}+1} \\
= & -\mathrm{h}_{2} \mathrm{~s}\left(\mathrm{iT} \mathrm{T}_{\mathrm{b}}+3 \mathrm{~T}_{\mathrm{s}}\right)^{*} \mathrm{e}^{-\mathrm{j} 2 \pi \mathrm{f}_{\mathrm{d}}\left(\mathrm{iT}_{\mathrm{b}}+3 \mathrm{~T}_{\mathrm{s}}\right)} \\
+ & \mathrm{h}_{1} \mathrm{~s}\left(\mathrm{iT}_{\mathrm{b}}+2 \mathrm{~T}_{\mathrm{s}}\right)^{*} \mathrm{e}^{-\mathrm{j} 2 \pi \mathrm{f}_{\mathrm{d}}\left(\mathrm{iT}_{\mathrm{b}}+2 \mathrm{~T}_{\mathrm{s}}\right)} \\
+ & \mathrm{n} 2
\end{aligned}
$$

$$
=\left[\begin{array}{ll}
h_{1} & h_{2}
\end{array}\right]\left[\begin{array}{c}
-s\left(\mathrm{iT}_{\mathrm{b}}+3 \mathrm{~T}_{\mathrm{s}}\right)^{*} \mathrm{e}^{-\mathrm{j} 2 \pi \mathrm{f}_{\mathrm{d}}\left(\mathrm{iT}_{\mathrm{b}}+3 \mathrm{~T}_{\mathrm{s}}\right)} \\
\mathrm{s}\left(\mathrm{iT}_{\mathrm{b}}+2 \mathrm{~T}_{\mathrm{s}}\right)^{*} \mathrm{e}^{-\mathrm{j} 2 \pi \mathrm{f}_{\mathrm{d}}\left(\mathrm{iT}_{\mathrm{b}}+2 \mathrm{~T}_{\mathrm{s}}\right)}
\end{array}\right]+
$$

n4

Where $\alpha_{2 i}, \beta_{2 i}, \alpha_{2 i+1}, \beta_{2 i+1}$ are the received symbol on the first, second, third and fourth time slot respectively, $\mathrm{h}_{1}$ is the channel from $1 \mathrm{st}$ transmit antenna to receiving antenna, $\mathrm{h}_{2}$ is the channel from $2 \mathrm{nd}$ transmit antenna to receiving antenna, $\mathrm{s}\left(\mathrm{iT}_{\mathrm{b}}\right), \mathrm{s}\left(\mathrm{iT}_{\mathrm{b}}+\mathrm{T}_{\mathrm{s}}\right), \ldots$ etc are the transmitted symbols, $\mathrm{n}_{1}$ and $\mathrm{n}_{2}$ are the noise on 1 st, 2nd time slots and, $\mathrm{n}_{3}$ and $\mathrm{n}_{4}$ are the noise on 3rd , 4th time slots respectively.

Define $\quad H=\left[\begin{array}{cc}h_{1} & h_{2} \\ h_{2}^{*} & -h_{1}^{*}\end{array}\right]$
The pseudo inverse $\mathrm{H}^{+}=\left(\mathrm{H}^{\mathrm{H}} \mathrm{H}\right)^{-1} \mathrm{H}^{\mathrm{H}}$

The estimate of $s\left(\mathrm{iT}_{\mathrm{b}}\right), \mathrm{s}\left(\mathrm{iT}_{\mathrm{b}}+\mathrm{T}_{\mathrm{s}}\right)$ is

$\left[\begin{array}{c}\mathrm{s}\left(\overline{\mathrm{iT}_{\mathrm{b}}}\right) \\ \mathrm{s}\left(\mathrm{iT}_{\mathrm{b}}+\mathrm{T}_{\mathrm{s}}\right)\end{array}\right]=\mathrm{H}^{+}\left[\begin{array}{l}\alpha_{2 \mathrm{i}} \\ \beta_{2 \mathrm{i}}\end{array}\right]$

$$
\left[\begin{array}{c}
\mathrm{n} 1 /\left|\mathrm{h}_{1}\right|^{2}+\left|\mathrm{h}_{2}\right|^{2} \\
\mathrm{n} 2 /\left|\mathrm{h}_{1}\right|^{2}+\left|\mathrm{h}_{2}\right|^{2}
\end{array}\right]
$$

$$
=s\left(\mathrm{iT}_{\mathrm{b}}\right)+\mathrm{s}\left(\mathrm{iT}_{\mathrm{b}}+\mathrm{T}_{\mathrm{s}}\right)+
$$

Such that the Doppler is canceled by a tapped delay line which is proposed, also the effect of noise is decreased .The same method is applied for the estimation of $s\left(\mathrm{iT}_{\mathrm{b}}+2 \mathrm{~T}_{\mathrm{s}}\right), \mathrm{s}\left(\mathrm{iT}_{\mathrm{b}}+3 \mathrm{~T}_{\mathrm{s}}\right)$ and so on.

Table 1 Simulation Conditions

\begin{tabular}{|c|c|}
\hline Helicopter & \\
\hline Maximum speed & $\mathrm{V}=68.4 \mathrm{~m} / \mathrm{s}$ \\
\hline Maximum acceleration & $\mathrm{A}=3.09 \mathrm{~m} / \mathrm{s}^{2}$ \\
\hline Modem & \\
\hline Modulation & BPSK \\
\hline Information data rate & $3600 \mathrm{bit} / \mathrm{s}$ \\
\hline Carrier frequency & $12.5 \mathrm{GHz}$ \\
\hline Demodulation & Coherent detection \\
\hline Forward error correction & \\
\hline Code & Convolutional \\
\hline Rate & $\mathrm{R}=1 / 2$ \\
\hline Constraint length & $\mathrm{K}=7$ \\
\hline g1 & $2 * 10^{\wedge}-3$ \\
\hline g2 & $5 * 10^{\wedge}-5$ \\
\hline
\end{tabular}

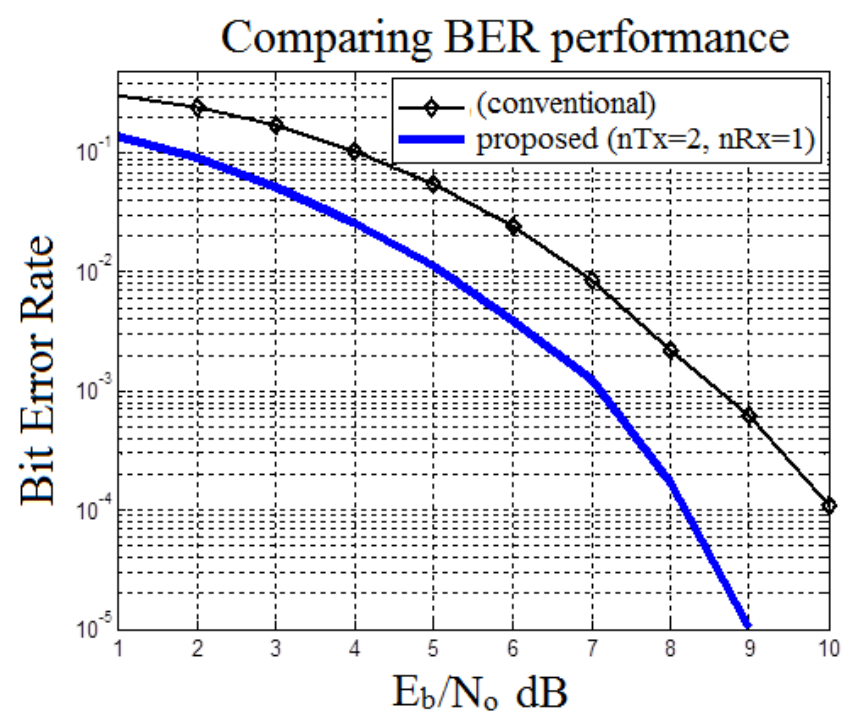

Fig.7 BER performance

Fig. 7 shows the BER performance. It is shown that the BER performance of the proposed scheme $(\mathrm{nTx}=2, \mathrm{nRx}=1)$ is better than that of the conventional scheme. 


\section{CONCLUSIONS}

In this paper, the proposed space time diversity combining scheme with accurate tapped delay line for helicopter satellite communications. Results of computer simulation show that the proposed tapped delay line tracks and removes time-varying Doppler shift exactly. It is also shown that the proposed scheme improves the BER performance of the previous conventional system combining scheme, and achieves the good BER performance agreeing well with the ideal one in the severe environment of the helicopter satellite communications.

\section{REFERENCES}

[1] K. Farazian, D. Divsalar, N. Golshan, T.K. Wu, and S. Hinedi, Helicopter Satellite Communication: Development of Low-Cost Real-Time Voice and Data System for Aeronautical Mobile Satellite Service (AMSS), ICUPC'93, pp.314-319, Ottawa Canada, Oct.12-15, 1993.

[2] K. Farazian, B. Abbe, D. Divsalar, D. Raphaeli, A. Tulintseff, T.K. Wu, and S. Hinedi, Development of LowCost Satellite Communications Sys- tem for Helicopters and General Aviation, Proc. of Dual-Use Heli/GA SATCOM Workshop, Aug.11, 1994.

[3] W.G. Cowley, M.P. Lavenant, and W. Zhang, A Mobile Satellite Modem for Helicopter Applications, IMSC'97, pp.479-484, Pasadena, USA, June 16-19, 1997.
[4] Pre-Detection Time Diversity Combining with Accurate AFC for Helicopter Satellite Communications. Toshiharu Kojima, Chuluunsukh Batzorig, and Tadashi Fujino Department of Information and Communication Engineering The University of Electro-Communications, Chofu-Shi, Tokyo, 182-8585, Japan.

[5] T. Uchiki, T. Kojima, M. Miyake, and T. Fujino, Carrier Slip Compen- sating Time Diversity Scheme for Helicopter Satellite Communication Systems, IEICE Trans. Commun., vol.E81-B, no.12, pp.2311-2317, Dec 1998

[6] T. Kojima, T. Uchiki, S. Ookubo, and J. Taniguchi, A Novel Accurate AFC Scheme for Helicopter Satellite Communications Combined with Time Diversity, IEEE, B Vol.J85-B No.10 pp.1728-1737, Oct 2002. (in Japanese)

[7] Huan-Bang Li, M. Sato, A. Miura, S. Taira, and H. Wakana, Ku-band helicopter satellite communications for on scene disaster Information transmission, PIMRC'04, pp.2794-2796, Sept.5-8, 2004.

[8] D. Wilcoxson, B. Sleight, J. O'Neil, and D. Chester, Helicopter Ku-band SATCOM on-the-Move, MILCOM'06, pp.1-7, Oct.23-25, 2006.

[9] Space-Time Processing for MIMO Communications John Wiley \& Sons Ltd, The Atrium, Southern Gate, Chichester, West Sussex PO19 8SQ, England 